\title{
Selenium phytoremediation study of contaminated soils by Vetiveria zizanioides and Medicago sativa
}

\author{
Samaneh Rasooli $^{*}$, Mojtaba Yousefirad ${ }^{2}$, Lobat Taghavi ${ }^{1}$
}

Received:20.08.2015

Revised:25.09.2015

Accepted: 30.10.2015

\begin{abstract}
With the growth of industry and the increasing consumption of chemicals, their entrance into water, soil and air results in the contamination of environment and consequently the danger that humans face, resulting from heavy metals, is felt more than ever before. Phytoremediation is an environmentally friendly method employing plants for removing pollutants from contaminated soils. The present study was carried out under greenhouse conditions using factorial experiment based on the randomized complete blocks design in three replications in order to analyze the phytoremediation ability of Vetiveria zizanioides and Medicago sativa in soils contaminated with selenium. Fivekilogram pots of Vetiveria zizanioides and Medicago sativa with 0,10 and $20 \mathrm{mg} / \mathrm{Kg}$ selenium in the soil were treated. Sixty days after the treatments, the plants were harvested. The results showed that in both Vetiveria zizanioides and Medicago sativa the effect of selenium in all the studied traits was significant $(\mathrm{P}<0.01)$. In both plants, with an increase in the amount of selenium in the soil, the dry weights of the organs decreased and the concentration of selenium in different organs increased. At every level of soil contamination the concentration of selenium in the different organs of Vetiver were higher than alfalfa. Since the transfer and absorption factors in the root and aerial parts of Vetiver were greater than that of Medicago, Vetiver has great ability in absorption and transfer of selenium from soil to shoot in comparison with alfalfa and is a more suitable plant for phytoremediation.
\end{abstract}

Key words: Hyper accumulation of heavy metals, Vetiver, Alfalfa, Selenium

\section{Introduction}

Soil, as an important part of environment, is the most important receiver of industrial and agricultural waste. As soon as such material enter the soil they become part of a cycle that affect life in different ways. Pollutants are among the factors causing disorder in the ecosystem among which heavy metals are of great importance due to being undegradable and having negative physiological effects on organisms in low densities (Khanghahi et al, 2013). Since the industrial revolution human activities, especially industrialization, urbanism and agricultural activities, have led to an increase in the movement and sediment of toxic heavy metals (Kilani Ben Rejeb et al, 2013) which have resulted in increased release of dangerous toxic metals in the environment (Gang $\mathrm{Wu}$ et al, 2009). Additionally, the contamination of habitats with heavy metals is permanent, unlike organic pollutants which disintegrate with biological activities of microorganisms present in soil and water, and chemical, light and thermal reactions. Therefore, the contamination of habitats with heavy metals has become an important issue in the world (Zolghi and Sanjani, Author's Address

${ }^{1}$ Department of Environment and Energy, Tehran Science and Research Branch, Islamic Azad University, Tehran.

${ }^{2}$ Department of Agronomy, Saveh Branch, Islamic Azad University, saveh, Iran.

Email: Samin.rasooli@gmail.com
2014).As an example, selenium is among contaminants that despite being a necessary microelement, its higher-than-necessary amount in the environment and the body causes disorders (Afyuni and Erfanmanesh, 2006).

Therefore, at present, one of the main and fundamental challenges in the field of environment is the gradual increase or the accumulation of the density of heavy metals due to not being biodegraded by microorganism (Akbarpour Sareskanroud et al, 2012) which has considerable dangers for human health and also the ecosystem (Liang Chen et al, 2013). Thus, the development of effective strategies regarding the modification of soils contaminated with heavy metals that do not affect the biological and environmental health of soil is necessary (Ying Ma et al, 2013). Phytoremediation is a technology based on the use of plants for removing, stabilizing and reducing organic and inorganic pollutants (Kilani Ben Rejeb et al, 2013) and is employed in the purification of soils, surface waters and underground waters. In other words, Phytoremediation, which is the use of plants and their rhizosphere, leads to the reduction of the density or the toxic effects of pollutants in the environment. This technology is novel, cost-effective, efficient, environment- and eco-friendly (Hazrat Ali et al, 2013) and is considered a challenging technology for in situ 
remediation of soil contaminated with heavy metals in large scales (Liang Chen et al, 2013).

This technology uses plants with high biomass levels that have the potential to accumulate metals 100 times more than non-accumulator plant species known as hyper accumulator plants. In this regard, it is important to benefit from endemic plants and also plant species that have great adaptability (Lorestani, 2009). In most studies, grass and legume were considered more than other plants used in pollution reduction (Shahriarietal, 2006). Medicago sativa L. (alfalfa) is a perennial plant from the leguminosae family. This plant contains strong root system which runs vertically deep into the soil and in some cases grows more than 5 meters (green nail). This plant is relatively resistant to cold and heat, salinity and dryness, and is a calciphile plant. It has high nutritional value and is able to modify drained, saline and poor lands with the ability to stabilize the atmospheric nitrogen through roots and root nodes (Mazaherilaghab, 1999).

Vetiveria zizanioides L. is from the poaceae family and has Indian origin. It has voluminous root system with delicate structures. It is also resistant to long term droughts, floods and water logging, and can resist temperatures ranging between -14 to 55 degrees centigrade. This plant has great efficiency in the absorption of $\mathrm{N}, \mathrm{P}$ or heavy metals in contaminated waters. It is also resistant to the presence of $\mathrm{Al}, \mathrm{Mn}$ and heavy metals such as $\mathrm{As}, \mathrm{Cd}, \mathrm{Cr}, \mathrm{Ni}, \mathrm{Pb}, \mathrm{Hg}, \mathrm{Se}$ and $\mathrm{Zn}$ which are present in the soil (Shooshtarian and Tehranifar, 2011).

Wide range of studies carried out on phytoremediation of soils contaminated with heavy metals show significant results. As an example, one of the studies proved that with an increase in the density of $\mathrm{Cd}$ in soil, the absorption and accumulation of $\mathrm{Cd}$ in the root and aerial tissues of an annual alfalfa specie increased. The rate of transfer factor (TF), plant extraction and $\mathrm{Cd}$ extraction coefficient prove that the specie under study possesses great ability in transferring $\mathrm{Cd}$ to aerial tissues (Mohammadi et al, 2010).

In a research it was observed that Vetiver is able to remediate and modify soils contaminated with heavy metals and nitrogen (Jalalipoor and Ghaemi, 2010). Another study proved that Vetiver has the ability to reabsorb $98 \%, 54 \%, 41 \%$ and $88 \%$ of the elements $\mathrm{Pb}, \mathrm{Cu}$, $\mathrm{Zn}$ and $\mathrm{Cd}$, respectively, which reduces the downward flow of heavy metals and their entrance into underground waters (Yahua Chen et al, 2004).

Therefore, the present study was carried out with the aim of investigating the possibility of removing Se from contaminated soil through phytoremediation using Medicago Sativa L. and Vetiveria Zizanioides L.. Medicago as an endemic Iranian legume and Vetiver as a foreign specie of poaceae were investigated in this study.

\section{Materials and Method}

The present research was carried out in April 2014 using pot experiment in the south of Hamedan (latitude of $34^{\circ}, 47^{\prime}, 12^{\prime \prime}$ north and longitude of $48^{\circ}, 30^{\prime \prime}$ east and altitude of $1870 \mathrm{~m}$ ). Before the cultivation soil sampling was performed and, therefore, the physical and chemical characteristics of the soil under study are displayed in table 1 .

Table 1: Analysis of soil sample

\begin{tabular}{|c|c|c|c|c|c|c|c|c|c|c|c|}
\hline $\begin{array}{c}\text { Soil pattern } \\
\text { (Contexture) }\end{array}$ & Clay\% & Silt\% & Sand\% & $\mathbf{N \%}$ & $\begin{array}{c}\mathbf{K} \\
(\mathbf{p p m})\end{array}$ & $\begin{array}{c}\mathbf{P} \\
(\mathbf{p p m})\end{array}$ & OC\% & TNV\% & $\mathbf{p H}$ & $\begin{array}{c}\text { EC } \\
(\mathbf{d s} / \mathbf{m})\end{array}$ & Parameter \\
\hline Lom & 18 & 31 & 51 & 0.11 & 210 & 25 & 1.13 & 19.5 & 8.2 & 0.15 & $\begin{array}{c}\text { Soil } \\
\text { content }\end{array}$ \\
\hline
\end{tabular}

The experiment was conducted using the factorial design in randomized complete blocks design with three replications. The first factor was the plant species employed in the study including Vetiver and Alfalfa. The second factor was the consumption of sodium selenite in three amounts including control sample, $19 \mathrm{mg}$ and 38 mg per $\mathrm{kg}$ soil (in which the amounts of selenium were zero consumption, $10 \mathrm{mg}$ and $20 \mathrm{mg}$ per $\mathrm{kg}$ soil, respectively).
In order to add heavy metal to soil, the required salt for each pot was weighed and dissolved in water considered for each $5 \mathrm{~kg}$ pot, and was later added to the soil in each pot. It must be mentioned that the amount of water for each pot was just enough for soil to reach field capacity. This amount was calculated $750 \mathrm{ml}$ for each pot. Then the soil contaminated with the relevant heavy metal was placed in plastic bags for three weeks in order for the heavy metal to be 
stabilized in the soil. After the preparation of soils, contaminated soil was placed in the pots, then Vetiver transplants and alfalfa seeds were transferred to the main pots and the plants were cultured based on the design. Five alfalfa plants and one Vetiver were kept in each pot.

After two months, Alfalfa and Vetiver were harvested, and their roots and shoots were separated, then characteristics such as dry and fresh weights (of roots and shoots) of the plants, and plant height were measured. The density of heavy metal in the roots and the shoots was determined in the laboratory using SEM EDAX. The aerial and root part of each plant were completely chopped using special scissors at the laboratory and then, using a laboratory mill, were milled, mixed and homogenized. The homogenized powder was poured onto small pieces of double-sided conductive carbon tape which were placed on lams with special coding. After ensuring that the powder was securely glued to the double-sided conductive carbon tape, the prepared samples were placed into the SEM EDAX machine seven by seven and the amount of heavy metal in each sample was measured. Then Translocation Factor (TF), Biological Concentration Factor (BCF) and Biological Accumulation Coefficient (BAC) were measured using the below formula for each plant and at each heavy metal level (Riffat Naseem Malik et al, 2010).

$\mathrm{TF}=[\text { Metals }]_{\text {shoot }} /[\text { Metals }]_{\text {root }}$

BAC $=[\text { Metals }]_{\text {shoot }} /[\text { Metals }]_{\text {soil }}$

$\mathrm{BCF}=[\text { Metals }]_{\text {root }} /[\text { Metals }]_{\text {soil }}$

Analysis of variance and the statistical analysis of the data were carried out using SAS and the comparison of the means of the data was done using the Duncan method at 5\% significance level. The charts were prepared using Microsoft Excel.

\section{Results \& Discussion \\ The density of selenium in root and shoot}

In table 2, related to the analysis of variance, it can be seen that the main effects such as plant type, the effect of the amount of selenium on selenium concentration in root and shoot were significant $(\mathrm{P}<0.01)$. Also, the interactions of research factors on the concentration of selenium in root and shoot were significant $(\mathrm{P}<0.01)$.

Table 2: the results of the analysis of variance of measured traits in the presence of research factors

\begin{tabular}{|c|c|c|c|c|c|}
\hline $\begin{array}{c}\text { Sources of } \\
\text { variation }\end{array}$ & df & $\begin{array}{c}\text { Root dry } \\
\text { weight }\end{array}$ & $\begin{array}{c}\text { shoot dry } \\
\text { weight }\end{array}$ & $\begin{array}{c}\text { Density of } \\
\text { selenium in } \\
\text { root }\end{array}$ & $\begin{array}{c}\text { Density of } \\
\text { selenium in } \\
\text { shoot }\end{array}$ \\
\hline Blook & 2 & ${ }^{\mathrm{ns}} 0.6116180$ & ${ }^{\mathrm{ns}} 0.0884101$ & ${ }^{\mathrm{ns}} 0.074112$ & ${ }^{\mathrm{ns}} 0.5374741$ \\
\hline (a) Plant type & 1 & ${ }^{* *} 304.8360482$ & ${ }^{* *} 994.2976470$ & ${ }^{* *} 2202.825204$ & ${ }^{* *} 3233.617350$ \\
\hline (b)Selenium & 2 & ${ }^{* *} 9.7294175$ & ${ }^{* *} 34.8636454$ & ${ }^{* *} 220.012363$ & ${ }^{* *} 87.452637$ \\
\hline $\mathbf{a}$ (b) & 2 & ${ }^{* *} 9.7124150$ & ${ }^{* *} 34.8196770$ & ${ }^{* *} 6.400254$ & ${ }^{* *} 61.447363$ \\
\hline Error & 15 & 0.2604060 & 0.230446 & 0.840674 & 0.479332 \\
\hline $\begin{array}{c}\text { Coefficient of } \\
\text { variation }\end{array}$ & 21.31 & 11.16 & 2.75 & 2.933016 \\
\hline
\end{tabular}

The results of the comparison of mean in table 3 show that the concentration of selenium in the root and shoot of Vetiver was more than its concentration in the root and shoot of Medicago. They also display that with an increase of selenium in soil, the selenium concentration in root and shoot of both plants increased in a way that at the third level of selenium consumption the highest concentration of selenium in plant organs was observed. At every soil selenium level, the concentration of selenium in the root and shoot of Vetiver was more than that of Medicago.

\section{Shoot dry weight}

In table 2, on analysis of variance, it is observed that main effects such as plant type and the effects of different amount of selenium on shoot dry weight was significant $(\mathrm{P}<0.01)$, and also the interactions of research factors proved to be significant $(\mathrm{P}<0.01)$. In the mean-comparison in table 3 it is shown that shoot dry weight in Vetiver was more than Medicago. The results of 
this table show that with an increase in soil selenium, shoot dry weight decreased in such a way that at the third level of selenium consumption the lowest shoot dry weight was observed. Also in Vetiver, with an increase in soil selenium density the shoot dry weight decreased but in Medicago no significant differences between different levels of selenium consumption were observed in shoot dry weight which shows that Medicago proved to be more resistant to increase in soil selenium in comparison with Vetiver. Considering the less metal density, the entrance of less metal to the plant may cause less damage to it (table 3).

\section{Root dry weight}

In table 2, displaying analysis of variance results, it is seen that the main effects such as plant type and the effect of the amount of selenium on root dry weight was significant $(\mathrm{P}<0.01)$, and also interactions of research factors proved to be significant $(\mathrm{P}<0.01)$. The results of mean comparison in table 3 meant that root dry weight in Vetiver was more than Medicago. These results also showed that, like the shoot, with an increase in soil selenium the root dry weight decreased in such a way that the lowest root dry weight was observed at the third level of selenium consumption. This table shows that, like shoot dry weight, an increase in soil selenium density in Vetiver root caused root dry weight reduction and in Medicago no significant differences were observed between selenium consumption levels in root dry weight.

Table 3: Mean comparison of the effects of studied factor levels on the investigated traits

\begin{tabular}{|c|c|c|c|c|}
\hline & $\begin{array}{c}\text { Root selenium } \\
\text { concentration } \\
(\mathbf{m g} / \mathbf{k g})\end{array}$ & $\begin{array}{c}\text { Shoot selenium } \\
\text { concentration } \\
(\mathbf{m g} / \mathbf{k g})\end{array}$ & $\begin{array}{c}\text { Root dry } \\
\text { weight } \\
(\mathbf{g})\end{array}$ & $\begin{array}{c}\text { Shoot dry } \\
\text { weight } \\
(\mathbf{g})\end{array}$ \\
\hline Control (Se1) & $30.2650 \mathrm{c}$ & $24.8508 \mathrm{a}$ & $3.0346 \mathrm{a}$ & $5.4020 \mathrm{a}$ \\
\hline $\begin{array}{c}\mathbf{1 0} \mathbf{~ m g} \\
\text { selenium } \\
(\text { Se2) }\end{array}$ & $32.5642 \mathrm{~b}$ & $21.0600 \mathrm{~b}$ & $2.5396 \mathrm{~b}$ & $4.7660 \mathrm{~b}$ \\
\hline $\begin{array}{c}\mathbf{2 0} \mathbf{~ m g} \\
\text { selenium } \\
\text { (Se3) }\end{array}$ & $26.9339 \mathrm{~b}$ & $15.8667 \mathrm{~b}$ & $0.0114 \mathrm{~b}$ & $0.0107 \mathrm{~b}$ \\
\hline $\begin{array}{c}\text { Medicago } \\
(\mathbf{P 1})\end{array}$ & $39.7078 \mathrm{a}$ & $31.3433 \mathrm{a}$ & $4.7633 \mathrm{a}$ & $8.5928 \mathrm{a}$ \\
\hline Vetiver (P2) & $\mathrm{E}$ & $\mathrm{E}$ & $0.0125 \mathrm{~d}$ & $0.0107 \mathrm{~d}$ \\
\hline P1Se1 & $25.91 \mathrm{~d}$ & $15.11 \mathrm{~d}$ & $0.0108 \mathrm{~d}$ & $0.012 \mathrm{~d}$ \\
\hline P1Se2 & $30.33 \mathrm{c}$ & $17.29 \mathrm{c}$ & $0.011 \mathrm{~d}$ & $0.0095 \mathrm{~d}$ \\
\hline P1Se3 & $\mathrm{E}$ & $\mathrm{E}$ & $6.057 \mathrm{a}$ & $10.79 \mathrm{a}$ \\
\hline P2Se1 & $39.22 \mathrm{~b}$ & $27.027 \mathrm{~b}$ & $5.068 \mathrm{~b}$ & $9.52 \mathrm{~b}$ \\
\hline P2Se2 & $43.93 \mathrm{a}$ & $34.5 \mathrm{a}$ & $3.465 \mathrm{c}$ & $5.47 \mathrm{c}$ \\
\hline P2Se3 & $43.93 \mathrm{a}$ & $34.5 \mathrm{a}$ & $3.465 \mathrm{c}$ & $5.47 \mathrm{c}$ \\
\hline
\end{tabular}

In every column and for every number, similar letters express no significant differences at $5 \%$ level.

\section{Translocation factors}

The results displayed in table 3 illustrate that with an increase in soil selenium from $10 \mathrm{mg}$ to $20 \mathrm{mg}$, accumulation in the root and shoot in Medicago reduced. The translocation factors also reduced with an increase in soil selenium density. So, it can be mention that at the third level of soil selenium density, Medicago did not show good ability in the absorption and transfer of selenium. The accumulation factor for the root was larger than that of shoot at both levels of selenium consumption which shows lack of suitable selenium transfer from root to shoot. The translocation factor also confirmed the low ability of Medicago in transferring selenium from root to shoot, since at both selenium consumption levels translocation factors were smaller than one. The investigations on Vetiver in table 4 express that with an increase in soil selenium, the accumulation factor in root and shoot reduces which shows that in high densities, as in Medicago, the ability to absorb selenium in Vetiver reduces. But, the translocation factor, 
contrary to Medicago, increased with an increase in soil selenium factor and was larger than that of Medicago at every selenium consumption level. Yet it was smaller than one at both consumption levels. This proves that Vetiver had better ability in transferring selenium to shoot and, therefore, was a better plant than Medicago for the phytoremediation of selenium. In sum, the translocation and accumulation factors in root and shoot of Vetiver were larger than that of Medicago which show better absorption and transfer of selenium in comparison with Medicago.

Table 4: The values of translocation and absorption factors

\begin{tabular}{|c|c|c|c|c|c|}
\hline \multicolumn{2}{|c|}{$\begin{array}{c}\text { BAC factor in } \\
\text { Medicago }\end{array}$} & \multicolumn{2}{c|}{ TF factor in Medicago } & \multicolumn{2}{c|}{ BCF factor in Medicago } \\
\hline Se & BAC & Se & TF & Se & BCF \\
\hline 10 & 75.36 & 10 & 0.601 & 10 & 125.263 \\
\hline 20 & 38.46 & 20 & 0.414 & 20 & 92.881 \\
\hline \multicolumn{2}{|c|}{ BAC factor in Vetiver } & \multicolumn{2}{|c|}{ TF factor in Vetiver } & \multicolumn{2}{c|}{ BCF factor in Vetiver } \\
\hline Se & BAC & Se & TF & Se & BCF \\
\hline 10 & 157.94 & 10 & 0.708 & 10 & 222.947 \\
\hline 20 & 103.881 & 20 & 0.960 & 20 & 108.157 \\
\hline
\end{tabular}

\section{Results and Discussion}

The results of the present research show that Vetiver has more ability in absorbing selenium from soil compared to Medicago, in a way that in all conditions selenium density was more in Vetiver than Medicago. In comparison with Medicago, Vetiver proved to have greater ability in phytoremediation and the accumulation of heavy elements in shoot. Adib et al. (2013) stated that the rate of pollution absorption by Vetiver was considerably high so that the least amount of soil pollution was observed after the treatment of Vetiver. The results of a research carried out by Emam Zadei (2013) illustrated that phytoremediation using Vetiver had great effect on pollution reduction in the environment. So it can be inferred that Vetiver, as a hyper accumulator, can be used to remediate contaminated soil.

The rate of selenium absorption using plants increases with its increase in the soil. In a research, Marry et al. (1986) pointed out that, the rate of metal absorption by plants increases as its density in the environment increases. Berrow et al. (1991) mention that the absorption of heavy metals from soil with the help of plants depends on type and density of metals in the soil, bioavailability of elements and plant species. Samani Majd et al. (2007) recognized phytoremediation as a suitable method for the remediation of contaminated soil and stated that the increase in soil contamination beyond plant tolerance causes toxicity and reduces efficiency in phytoremediation.
On the other hand, with an increase in selenium consumption density, its density in different organs increases. Root periphery and root secretion may change the biochemical conditions and as a result pollutants are sedimented on the roots or inside them. Pollutants may remain on or inside the root or be transferred to different parts of the plant after absorption depending on the type of pollutant, density and plant type. One of the points to be mentioned here is the many density changes in the shoot compared to the root and that the density of selenium in the shoot of Vetiver is more than that of the root. This means that transfer from root to shoot is well done which is in accordance with the results of Haji Boland (2007) conducted on Brassica oleraceae, but the conditions were vice versa for Medicago. Based on the findings of Cheraghi et al (2010) and Zacchini et al (2008) the specie whose BAC is larger than 1 and its TF is smaller than 1 is suitable for phytostabilization, and the specie whose BAC in shoot is larger than 1 is suitable for phytoextraction. According to previous research, in phytoremediation of heavy metals the ratio of element transfer from root to shoot (TF) is important and necessary.TF increases with an increase in soil selenium and is larger than 1 at both consumption levels. This shows that Vetiver has great ability in transferring selenium from root to shoot.

In the research conducted by Jalalipoor and Ghaemi (2010) it was stated that Vetiver is able to remediate soils contaminated with heavy metals and nitrogen in the remediation of soil pollutants. To this end Vetiver can be used to 
remediate and modify soil quality to reach desired standards. The findings of the above mentioned study are similar to the findings in Farzanegan et al (2011). Based on the results it can be understood that Vetiver displayed better ability in phytoremediation in comparison with Medicago.

\section{References}

Akbarpoor, Fatemeh and Farhad Sadri, Daryoush Golalizadeh. 2012. Phytoremediation of contaminated soils to some heavy metals using endemic plants in Arasbaran protected area, jurnal of water and soil conservation, year 1, No. 4 .

Erfanmanesh Majid, Majid Afyouni. 2006. Environmental pollution (water, soil and air), Esfehan, Arkan publications.

Gang Wu, Hubiao Kang, Xiaoyang Zhang, Hongbo Shao, Liye Chu, Chengjiang Ruan. 2009. "A critical review on the bio-removal of hazardous heavy metals from contaminated soils: Issues, progress, eco-environmental concerns and opportunities: A Review "Journal of Hazardous Materials,vol. $174: 1-8$.

Hazrat Ali , Ezzat Khan , Muhammad Anwar Sajad. 2013. "Phytoremediation of heavy metals - Concepts and applications: A Review "Chemosphere, vol.91 : 869881.

Kilani Ben Rejeb, TaharGhnaya, HanenZaier, MaaliBenzarti, RaoudhaBaioui, Rim Ghabriche, MeriemWali, Stanley Luttsb, ChedlyAbdelly. 2013. "Evaluation of the $\mathrm{Cd} 2+$ phytoextraction potential in the xerohalophyteSalsola kali L. and the impact of EDTA on this process"Ecological Engineering, vol. 60: 309315.

Liang Chen , ShenglianLuo , Xiaojie Li, Yong Wan, Jueliang Chen , Chengbin Liu. 2013. "Interaction of CdhyperaccumulatorSolanumnigrum $\mathrm{L}$. and functional endophyte Pseudomonas sp. Lk9 on soil heavy metals uptake" Soil Biology \&Biochemistry,vol. 68: 300-308.
Lorestani Bahareh. 2009. The investigation of the amount of heavy metals in Hamedan province contaminated soil and the feasibility of removing them using hyperaccumulators. Master's dissertation.

Mohammadi Morteza, Davood Habibi, Mohammadreza Ardakani, Ahmad Asgharzade. 2010. The evaluation of the power of absorption and accumulation of annual Medicago Scutellata in soils contaminated with $\mathrm{Cd}$. Journal of plant ecophysiology, volume 2, No. 3 .

Riffat Naseem Malik, Syed Zahoor Husain and Ishfaq Nazir. 2010." Heavy metal contamination and accumulation in soil and wild plant species from industrial area of Islamabad, Pakistan" Journal of Environmental Biology Laboratory,Department of Plant Sciences, vol 42(1): 291-301.

Shahriyari Hossein, Gholamreza Firoozabadi, Daryoush Minaee, Mona Padidaran. 2006. The effect of mixed plants alfalfa (Medicago Sativa) and Fescue (Festuca arundinacea) on the phytoremediation of light crude oil in soil, environmental sciences 13 .

Yahua Chen , Zhenguo Shen1, Xiangdong Li. 2004. "The use of vetiver grass (Vetiveriazizanioides) in the phytoremediation of soils contaminated with heavy metals" Applied Geochemistry, Vol. 19: 1505-1654.

Ying Ma, Mani Rajkumar, YongmingLuo, Helena Freitas. 2013. " Phytoextraction of heavy metal polluted soils using Sedum plumbizincicola inoculated with metal mobilizing Phyllobacteriummyrsinacearum RC6b”Chemosphere ,vol. 93: 1386-1392.

Ying-Ning Ho, Ju-Liang Hsieh, Chieh-Chen Huang. 2013. "Construction of a plant-microbe phytoremediation system: Combination of vetiver grass with a functional endophytic bacterium, Achromobacterxylosoxidans F3B, for aromatic pollutants removal'BioresourceTechnology,vol. 145:43-47.

Ying Ying Li ,Hong Yang 2013."Bioaccumulation and degradation of pentachloronitrobenzene in Medicago sativa”Journal of Environmental Management,vol. 119 : 143-150. 